Article

\title{
Experimental Determination of the Friction Factor in a Tube with Internal Helical Ribs
}

\author{
Sławomir Grądziel ${ }^{1, *}$ and Karol Majewski ${ }^{2}$ \\ 1 Institute of Thermal Power Engineering, Cracow University of Technology, Al. Jana Pawła II 37, \\ 31-864 Kraków, Poland \\ 2 EthosEnergy, ul. Paprotna 12A, 51-117 Wrocław, Poland; Karol.Majewski@ethosenergygroup.com.pl \\ * Correspondence: gradziel@mech.pk.edu.pl
}

Received: 26 November 2018; Accepted: 11 January 2019; Published: 15 January 2019

\begin{abstract}
Due to the extended geometry of internally rifled tubes with helical ribs, the rate of convective heat transfer within them is much higher compared to smooth tubes. Simultaneously, a rise in the contact surface area between the fluid and the solid body increases the friction factor. This paper presents the results of experimental testing performed to determine the friction factor in an internally rifled tube with helical ribs. The tests were carried out on a purpose-built test stand. The tested object was a rifled tube used in the evaporator of a once-through supercritical power boiler operating in a power plant in Poland. The friction factor results obtained from testing are compared to the results of calculations performed by means of correlations known from the literature. Finally, using experimental data, a new correlation is developed that enables the determination of the friction factor in internally rifled tubes with helical ribs.
\end{abstract}

Keywords: smooth tubes; helically internally ribbed tube; friction factor; pressure losses; supercritical power boiler

\section{Introduction}

Heat exchangers with finned or ribbed tubes are common in thermal engineering. In most cases, the heat transfer surface area is extended on the side of the fluid, which is characterized by a lower thermal capacity. This is why fins and ribs are so popular in gas-liquid exchangers on the side of the gaseous medium. Different solutions are much less common. Ribs/fins on the side of the liquid phase medium are used more often in cases where departure from nucleate boiling may occur due to operating conditions. This happens in the evaporators of cooling systems and the tight walls of the power boiler evaporator. The heat transfer surface area is most often extended on the inside using inserts that enhance the flow turbulence (e.g., in the form of twisted tapes), as well as straight fins or fins inclined at appropriate angles. Such solutions increase the heat transfer surface area, enhance the flow turbulence, and reduce the tube wall temperature. Additionally, in the case of multi-phase flows, the centrifugal force arising in the fluid keeps the water film on the wall of the tubes. The downsides of these solutions include higher manufacturing costs and an increase in pressure losses as compared to flows through smooth tubes of the same hydraulic diameter [1].

Carnavos [2] was one of the first to carry out comprehensive work on tubes with internal ribs. He presented testing results obtained during the cooling of air. The analysis concerns flow through 21 tubes. The tubes' inner diameters ranged from 3.18-23.8 $\mathrm{mm}$. Inside the analyzed tubes were 5-41 ribs with different geometries. In most tubes, they were arranged longitudinally (helical rib angle $=0^{\circ}$ ); in six cases, the helical angle varied from $2.5^{\circ}-20^{\circ}$. Using the experimental data, the author related the geometrical dimensions and the helical angles of the ribs to the heat transfer coefficient and the friction factor. Carnavos [2] also estimated that using tubes with internal ribs could reduce the 
number of tubes needed in the exchanger by a few dozen percent. Another advantage he observed was the potential increase in the power of existing heat exchangers without having to increase the medium mass flow rate.

Similar studies were performed by Webb and his team [3]. Seven rifled tubes with internal helical ribs were tested. Their inner diameters were $15.54 \mathrm{~mm}$. The tests were carried out using water for Prandtl numbers from the range of 5.08-6.29. The tubes had 18-45 ribs, with rib helical angles ranging from $25^{\circ}-45^{\circ}$ and height from $0.33-0.55 \mathrm{~mm}$. These measurements made it possible to obtain correlations enabling calculation of the friction factor and the Chilton-Colburn $\mathrm{j}$ factor for single-phase flows. Knowing the $\mathrm{j}$ factor and the definition of the Stanton and the Nusselt criterial numbers, it is possible to find the heat transfer coefficient [4]. The authors recommended the developed formulae as fit for commercially applied rifled tubes with diameters similar to that of the tubes used during experimentation.

Zdaniuk's team performed similar tests [5]. Measurements were made during water flow through tubes with internal helical ribs. The rib helical angles were in the range of $25^{\circ}-48^{\circ}$, and the number of ribs in the cross-section ranged from 10-45. All tubes used in testing had outer diameters of about $17.4 \mathrm{~mm}$. Rib height ranged from $0.31-0.51 \mathrm{~mm}$. The obtained measuring data were compared with the Blasius and the Dittus-Boelter equations for linear friction-related pressure losses (the friction factor) and for convective heat transfer, respectively. The results were also used to develop the friction factor and the heat transfer coefficient formulae. The formulae were found using a group of five parameters [6], also using neural networks to calculate the required quantities and constants [7].

In their research, Cheng and Chen studied pressure drops in flows through a rifled and a smooth tube [8]. The rifled and smooth tube inner diameters were 11 and $15 \mathrm{~mm}$, respectively. During the testing, the tubes were installed vertically, and the length of the heated segment totaled $2500 \mathrm{~mm}$. Water and kerosene were used as the working medium. It follows from the experiments that in the case of a two-phase flow of the used mediums, the friction-related pressure losses in tubes with internal helical ribs range from 1.6-2.7 times higher compared to those arising in smooth tubes. This is an effect of the disturbance caused by the ribs in the flow of the boundary layer. In particular, the impact is noticeable for high Reynolds numbers. Cheng and Chen proposed an equation enabling the determination of the two-phase flow multiplier for the tube with internal helical ribs used during testing [8].

Weiguo et al. [9] examined the heat transfer coefficient in helically ribbed tubes arranged horizontally. The heat transfer was observed in a tube with outer and inner diameters of 25 and $20 \mathrm{~mm}$, respectively. The ribs were $1 \mathrm{~mm}$ high, and their pitch was $12 \mathrm{~mm}$. The working medium used during the testing was Therminol-55 oil [10]. The obtained results point to a rise in the Reynolds number and the friction factor compared to smooth tubes. Moreover, the results of the experimental testing were compared with the modeling results.

Apart from the publications mentioned above, experimental testing of tubes with internal helical ribs has been carried out, mainly in relation to heat transfer. The experiments were performed for different fluids and tubes with different geometries. Most of the tested tubes had inner diameters smaller than $20 \mathrm{~mm}$. Such tubes can be used in the design of industrial heat exchangers, or they make up a part of cooling or air-conditioning installations. First, tests were carried out using air. Now, water samples under different pressures or cooling agents are commonly used as the working medium. Details of experimental testing to determine pressure losses in internally ribbed tubes are presented below in Table 1. 
Table 1. Experimental testing to determine pressure losses in internally ribbed tubes.

\begin{tabular}{ccccc}
\hline Researcher & Working Fluid & $\begin{array}{c}\text { Inner Diameter } \\
\mathbf{d}_{\mathbf{i}} \text { [mm] }\end{array}$ & $\begin{array}{c}\text { Pitch } \\
\mathbf{p} \text { [mm] }\end{array}$ & $\begin{array}{c}\text { Rib Height } \\
\mathbf{e} \text { [mm] }\end{array}$ \\
\hline Ackerman [11] & Supercritical pressure water & 18 & 21.8 & 0.9 \\
Gee and Webb [12] & Air & 25.4 & 3.81 & 0.25 \\
Zimparov et al. [13] & Water & 25.0 & $6.5-16.9$ & $0.44-1.18$ \\
Ravigururajan and Bergles [14] & Water and air & $14.0-22.86$ & $4.16-10.16$ & $0.89-1.78$ \\
Cheng et al. [15] & Oil & 11.0 & 5.5 & 0.5 \\
Dong et al. [16] & Water and oil & $19.0-25.0$ & $10.0-12.0$ & $0.39-0.8$ \\
Barba et al. [17] & Water & 11.5 & 1.5 \\
Vicente et al. [18] & Water and glycol & 18.0 & $10.9-22.1$ & $0.42-1.03$ \\
Wang et al. [19,20] & Supercritical pressure water & 18.6 & 11.6 & 1.2 \\
Yang et al. [21] & Two-phase mixture & 21.0 & 22.7 & 0.85 \\
Khoeini et al. [22] & R-134a & 9.52 & 8.0 & 1.5 \\
Ji et al. [23] & Water & $18.9-19.1$ & - & $0.39-0.45$ \\
Lu et al. [24] & Liquid salt & 10.2 & 3.2 & $0.38-0.76$ \\
Li et al. [25] & Supercritical CO ${ }_{2}$ & 16.5 & - & 0.85 \\
Yang et al. [26] & Supercritical CO & $10.0-20.0$ & $0.25-0.90$ \\
Weiguo et al. [27] & Therminol 55 & 9.0 & 21.0 & 0.85 \\
Zhang et al. [28] & Supercritical pressure water & 20.62 & 12.87 & 1.25
\end{tabular}

The analysis presented above proves that very few experimental tests are performed on internally rifled tubes applied in industrial installations such as power boilers. Pressure-related losses arising in boiler evaporators made of rifled tubes have so far been determined using correlations developed for tubes installed in compact heat exchangers with different fluids and smaller diameters. This paper presents experimental testing carried out on a newly-built stand equipped with a tube with internal helical ribs which found its application in the evaporator of a supercritical circulating fluidized bed (CFB) boiler. The analyzed tube's inner diameter is almost 2.5 times larger compared to the tubes presented in Table 1. Based on the obtained experimental data, a correlation is developed that makes it possible to determine the pressure loss coefficient for a tube with the appropriate geometrical dimensions. The equation's general form is selected so that a comparison with existing results of tests performed on rifled tubes can be made.

\section{Friction Factor in Smooth and Rifled Tubes}

The smooth tube friction factor $f$ is determined based on the value of the Reynolds number. For smooth tubes in single-phase laminar flows $(R e<2300)$, the Hagen-Poiseuille relation is used:

$$
f=\frac{64}{R e}
$$

For fully developed flows, the Blasius equation is applied [4]:

$$
f=\frac{0.316}{R e^{0.25}}
$$

and for higher Reynolds numbers $\left(\operatorname{Re}>10^{5}\right)$, the McAdams Equation [30] can be used:

$$
f=\frac{0.184}{R e^{0.2}}
$$

In many situations, the friction factor $f$ must be found iteratively. In engineering calculations, it is possible to use correlations that do not require iterations. The Churchill equation can serve as an example here [30]:

$$
f=\frac{1.325}{\left[\ln \left(\frac{\varepsilon}{3.7 d}+\frac{5.74}{R e^{0.9}}\right)\right]^{2}}
$$


Similar correlations were proposed by Moody [30]:

$$
f=0.0055\left[1+\left(2 \cdot 10^{4} \frac{\varepsilon}{d}+\frac{10^{6}}{R e}\right)^{0.333}\right]
$$

Vennard [30]:

$$
f=\left[1.14+2 \log _{10} \frac{d}{\varepsilon}\right]^{-2}
$$

and Haaland [30]:

$$
\frac{1}{\sqrt{f}}=-1.8 \log _{10}\left[6.9 \operatorname{Re}+\left(\frac{\varepsilon}{3.7 d}\right)^{1.11}\right]
$$

Thermal and flow conditions change, depending on the tube's geometrical dimensions, the rib helical angles, and the number of ribs in the cross-section. The most essential geometrical dimensions of rifled tubes are presented in Figure 1.
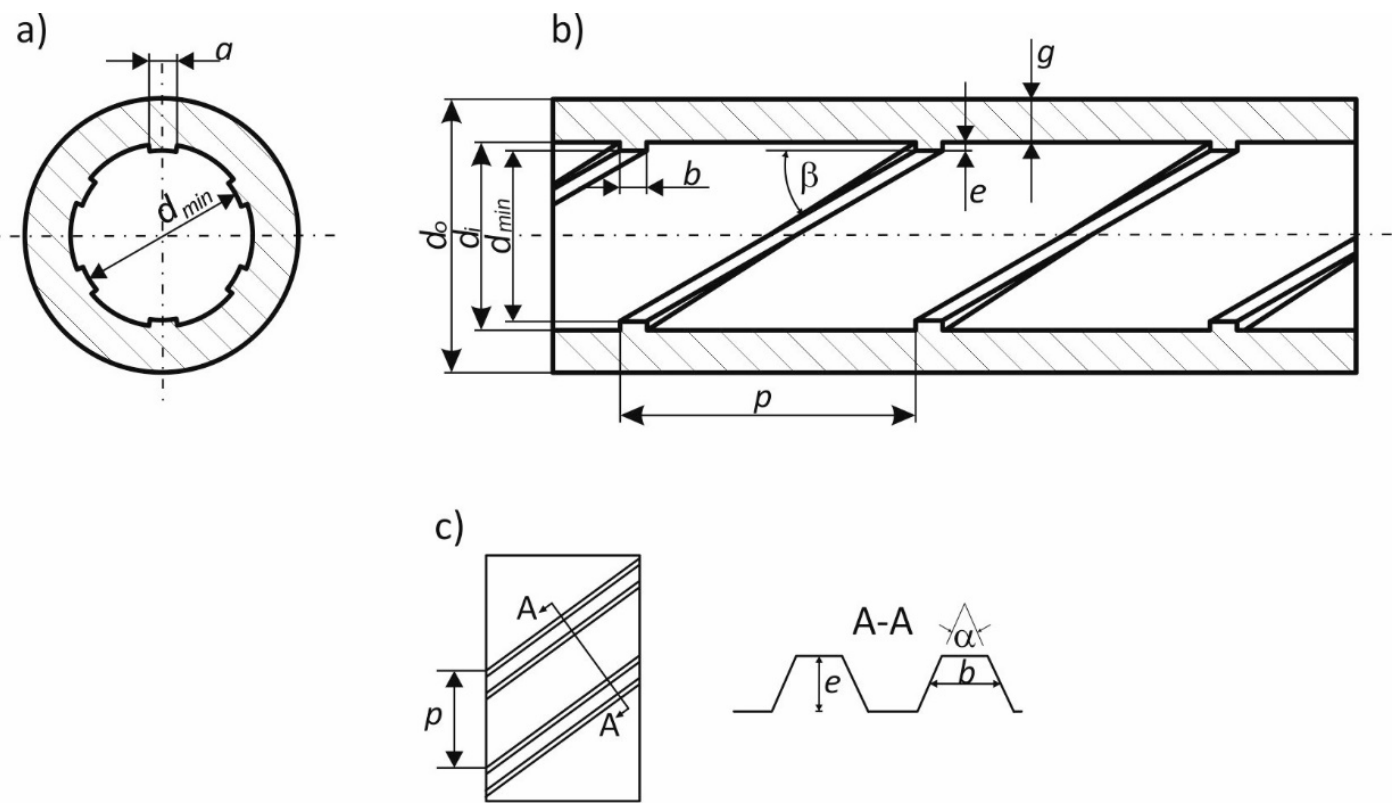

Figure 1. Geometrical dimensions of rifled tubes: (a) Transverse section, (b) longitudinal section, (c) rib detail. $a$-Rib width at the base; $b$-rib average width; $d_{0}$ - outer diameter; $d_{i}$-inner diameter (with no ribs); $d_{\text {min }}$-minimum diameter with ribs; $e$-rib height; $g$ - wall thickness; $\mathrm{p}$-rib pitch; $\alpha$-rib extension apex angle; $\beta$-rib helical angle.

In many works, the friction factor for rifled tubes is found through a comparison with smooth tubes. The factor can be determined using the relations described above.

The friction factor in rifled tubes is calculated as [14]:

$$
\begin{array}{r}
\frac{f}{f_{F}}=\left\{1+\left[9.1 R e^{\left(0.67-0.6 \frac{p}{d_{i}}-0.49 \frac{\beta}{90}\right)} \cdot\left(\frac{e}{d_{i}}\right)^{\left(1.37-0.57 \frac{p}{d_{i}}\right)} \cdot\left(\frac{p}{d_{i}}\right)^{\left(-0.00000166 R e-0.33 \frac{\beta}{90}\right)} .\right.\right. \\
\left.\left.\cdot\left(\frac{\beta}{90}\right)^{\left(4.59+0.000000411 R e-0.15 \frac{p}{d_{i}}\right)} \cdot\left(1+\frac{2.94}{n_{c}}\right) \sin \beta\right]^{\frac{15}{16}}\right\}^{\frac{15}{16}}
\end{array}
$$

Equation (8) holds when $0.1<e / d_{i}<0.2,0.1<p / d_{i}<7.0,0.3<\beta / 90<1.0$, $5000<\operatorname{Re}<250,000$, and $0.66<\operatorname{Pr}<37.6$. The formula takes into account the number of sharp edges of ribs $n_{c}$ in contact with the fluid. For triangular and rectangular ribs, the parameter takes the value of 2; for rounded ribs, it approaches infinity. 
One of the first works on the determination of the friction factor in tubes with internal ribs, including internal helical ribs, was carried out by Carnavos. He put forward a correlation that makes it possible to relate linear frictional losses to geometrical dimensions and the number of ribs [2]:

$$
f_{F}=0.046 \operatorname{Re}^{-0.2}\left(\frac{A_{n}}{A_{x s}}\right)^{-0.5}(\sec \beta)^{0.75}
$$

where:

$A_{n}$-tube cross-section surface area (ribs not taken into account);

$A_{x s}$-tube cross-section surface area minus the surface area occupied by ribs:

$$
A_{x s}=A_{n}-N \cdot e \cdot b
$$

Equation (9) was developed based on the testing of 21 tubes. For most of them, the rib helical angle was $0^{\circ}$. For six of them, the angle was included in the range from $2.5^{\circ}$ to $20^{\circ}$. Equation (9) is valid for: $3.18 \mathrm{~mm}<d_{i}<23.8 \mathrm{~mm}, 5<N<40,2.5^{\circ}<\beta<20^{\circ}$, and 10,000 $<R e<120,000$.

The application scope of Equation (9) is limited because the formula was derived based on measurements in tubes with relatively high ribs arranged either along the tube axis or at a slight helical angle. Based on experimental works, research teams led by Zdaniuk developed a correlation for the determination of friction-related pressure losses in tubes with internal helical ribs:

$$
\begin{gathered}
f_{F}=0.128 R e^{-0.305} N^{0.235}\left(\frac{e}{d_{i}}\right)^{0.319} \beta^{0.397} \\
\ln \left(f_{F}\right)=17.893\left(\frac{e}{d_{i}}\right)+17.799 \frac{\frac{e}{d_{i}} \beta}{N}-5.283 \cdot 10^{-5} N \cdot \beta-692.383 \frac{\frac{e}{d_{i}}}{N}-0.33 \ln (R e)-1.027 \\
f_{F}=0.120 R e^{-0.260} N^{0.267}\left(\frac{e}{d_{i}}\right)^{0.385} \beta^{0.276}
\end{gathered}
$$

Equations (11), (12), and (13) hold when $0.0199<\frac{e}{d_{i}}<0.0327,10<N<45,25^{\circ}<\beta<48^{\circ}$, and $12,000<\operatorname{Re}<60,000$.

The coefficients used in Equation (11) are calculated by means of the least squares method based on experimental data [5]. The same measuring results are used to select the coefficients in Equation (12). The difference is related to the proposal for a correlation based on five simple groups of parameters [7]. Neural networks and measuring data from a few other publications were used in Reference [6], enabling selection of the coefficients in Equation (13).

The development of the experimental data obtained from the works led by Webb made it possible to derive a correlation that relates linear frictional pressure losses (the friction factor) to the rifled tube geometrical dimensions and to the Reynolds number. The friction factor was derived based on the results of measurements performed during the flow of water through seven tubes with inner diameters of $15.54 \mathrm{~mm}$ and with different numbers of ribs of varied geometry. The developed equation has the following form [3]:

$$
f_{F}=0.108 R e^{-0.283} N^{0.221}\left(\frac{e}{d_{i}}\right)^{0.785} \beta^{0.78}
$$

Seven rifled tubes with inner diameter $d_{i}=15.54 \mathrm{~mm}$ were tested to develop Equation (14). Equation (14) holds when $0.0212<\frac{e}{d_{i}}<0.0354,18<N<45,25^{\circ}<\beta<45^{\circ}$, and 15,000 $<\operatorname{Re}<50,000$. 
The authors recommend that Equation (14) should be used for tubes with similar diameters and a similar number of ribs with similar geometry. Due to the fact that the presented equations were developed based on experimental data obtained for tubes with different internal geometries, the curves illustrating changes in the friction factor differ from each other. Figure 2 presents a comparison of the friction factor curves plotted for selected equations for tubes with internal helical ribs (Equations (9), (11), and (14)) and one plot for the Blasius equation for smooth tubes (Equation (2)) [31].

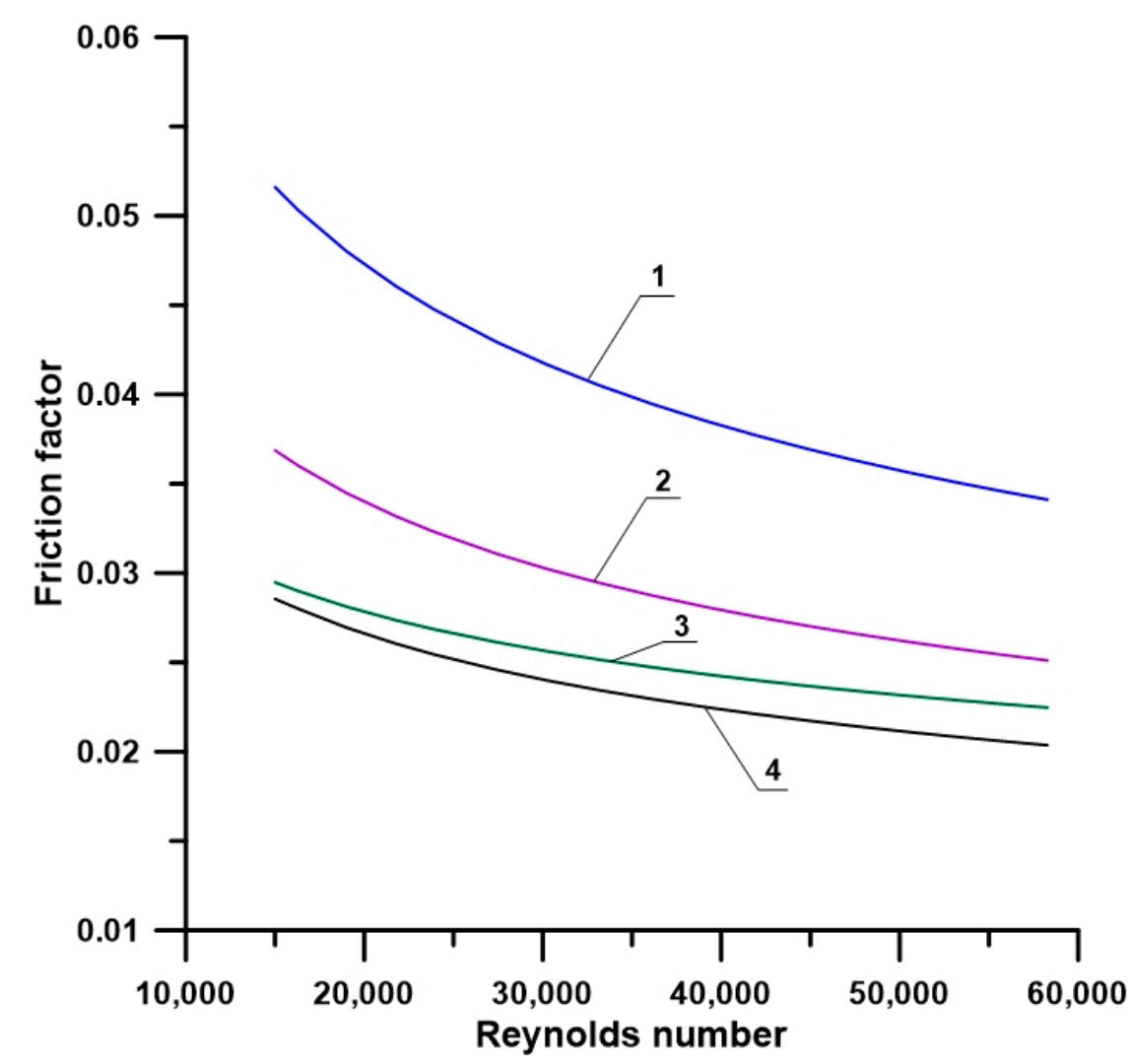

Figure 2. Comparison of the friction factor curves plotted for tubes with internal helical ribs and smooth tubes. Regarding internally ribbed tubes: 1-Equation (11); 2-Equation (14); 3-Equation (9). Regarding smooth tubes: 4-Equation (2).

In the case of a smooth tube and an internally ribbed tube with the same inner diameter, a considerable rise in the friction factor value can be observed. The differences between the used correlations result from the differences in the geometries of the tested tubes. In the case of Equation 9, experiments concerned the flow through a tube with straight ribs, which makes it impossible to fully simulate the phenomena arising in the fluid helical flow.

\section{Test Stand for Experimental Determination of Pressure Losses in Rifled Tubes}

During the study, linear pressure losses due to the friction in internally ribbed tubes were found on a dedicated test stand. Diagrams illustrating stands used for such experimental testing are presented in References [5,8,21,31-33]. The diagram of the test stand used herein is presented in Figure 3 below. 


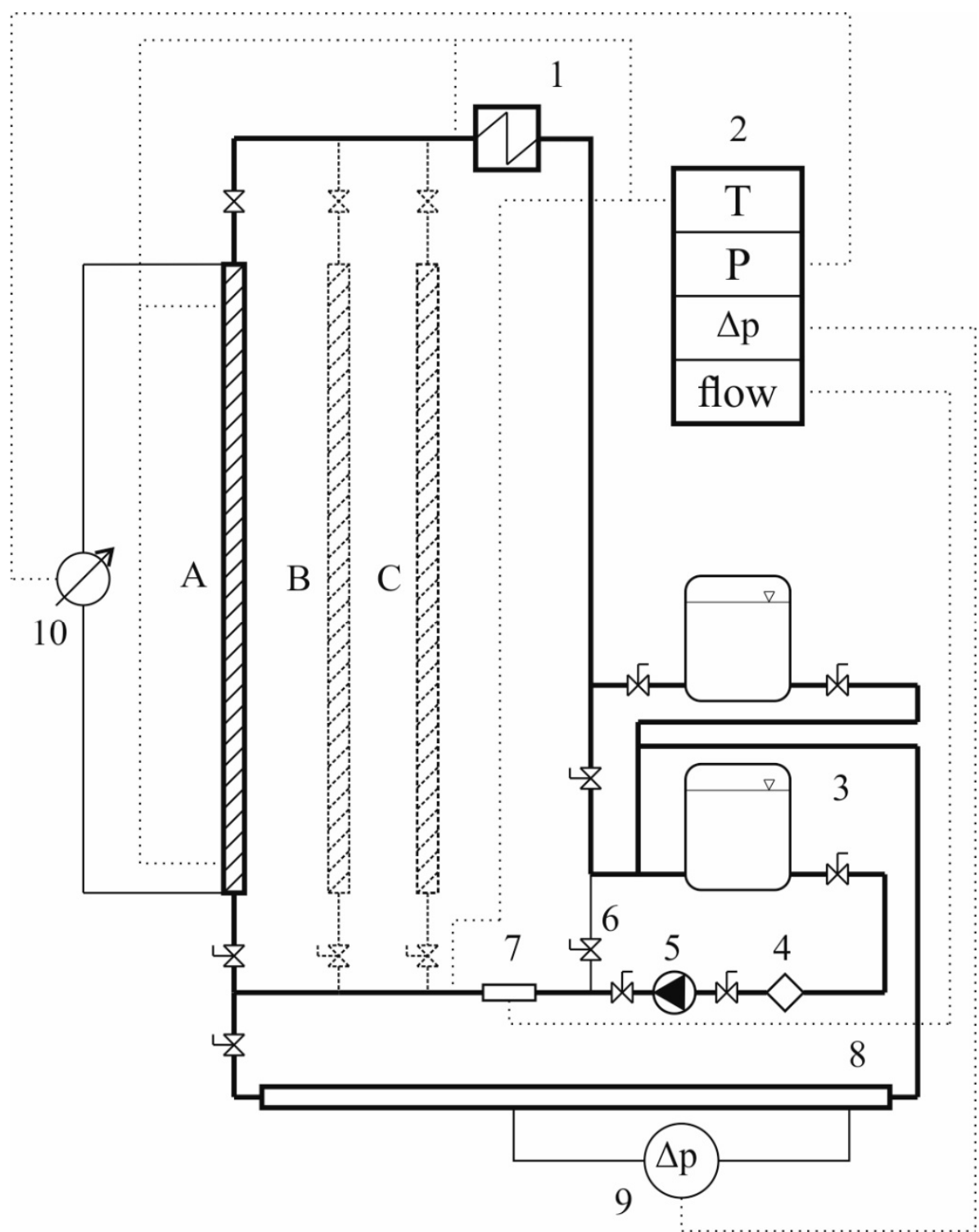

Figure 3. Diagram of the test stand. A-rifled tube (to determine the heat transfer coefficient); B, C - other tested objects; 1 - cooler; 2 -data acquisition system; 3 -circulating water containers; 4-contamination filter; 5-circulating pump; 6-bypass; 7-flowmeter; 8-horizontal segment for frictional loss testing; 9-differential pressure meter; 10-heating elements power control system.

The object of the experimental testing was a tube with internal helical ribs which finds application in a supercritical Circulating Fluidized Bed (CFB) boiler. The markings of the tube's geometrical dimensions are shown in Figure 1, and the characteristic quantities are listed in Table 2. The tube is made of $13 \mathrm{CrMo} 44$ steel. 
Table 2. Characteristic dimensions of the experimentally-tested tube with internal helical ribs [34].

\begin{tabular}{cc}
\hline Characteristic Dimension & Value \\
\hline Outer diameter, $d_{o}$ & $50.8 \mathrm{~mm}$ \\
Inner diameter (without ribs), $d_{i}$ & $34.9 \mathrm{~mm}$ \\
Minimum diameter, $d_{\text {min }}$ & $32.9 \mathrm{~mm}$ \\
Wall thickness, $g$ & $7.95 \mathrm{~mm}$ \\
Rib height, $e$ & $1 \mathrm{~mm}$ \\
Pitch, $p$ & $30 \mathrm{~mm}$ \\
Rib width at the base, $a$ & $5 \mathrm{~mm}$ \\
Rib average width, $b$ & $4.5 \mathrm{~mm}$ \\
Rib apex angle, $\alpha$ & $45^{\circ}$ \\
Rib helical angle, $\beta$ & $30^{\circ}$ \\
Number of ribs in the cross-section, $N$ & 6 \\
\hline
\end{tabular}

The experimental tests were carried out using a $3 \mathrm{~m}$ long tube placed horizontally. The tube length was selected to ensure a sufficient entrance length for the fluid flow. The entrance length totalled $1.5 \mathrm{~m}$, which is more than 40 -fold the inner diameter. If the obtained results are to be related to smooth tubes, it is necessary to know the hydraulic diameter, which is calculated as follows:

$$
d_{h}=\frac{4 A}{O}
$$

where:

$A$-tube cross-section surface area, $\mathrm{m}^{2}$;

$\mathrm{O}$-wetted perimeter, $\mathrm{m}$.

For the tube used in the experiment, the hydraulic diameter cannot be estimated easily. A cross-section of the tube contoured in a CAD program was used. The cross-section under consideration is shown in Figure 4. The cross-section illustrating the helical arrangement of the ribs is presented in Figure 5.

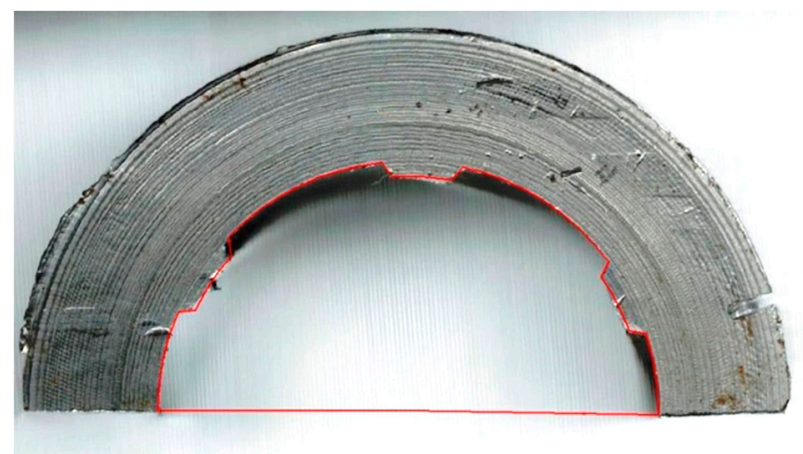

Figure 4. Cross-section of the tube with internal helical ribs with a marked contour.

The measured surface area of the fluid flow cross-section totals $924.34 \mathrm{~mm}^{2}$, and the tube perimeter, including the ribs, is $114.44 \mathrm{~mm}$. The hydraulic diameter calculated using Equation (15) is $32.305 \mathrm{~mm}$. This value is used in further calculations to compare data obtained from measurements with theoretical computations related to smooth tubes. 


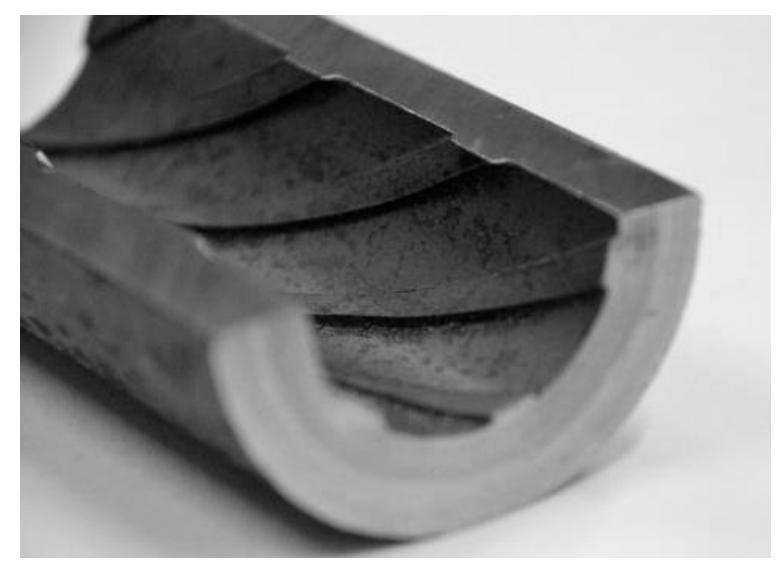

Figure 5. A cross-section of the tube with internal helical ribs.

The differential pressure during adiabatic flows through the horizontal segment was measured using a PXWD differential pressure transducer (Figure 6).

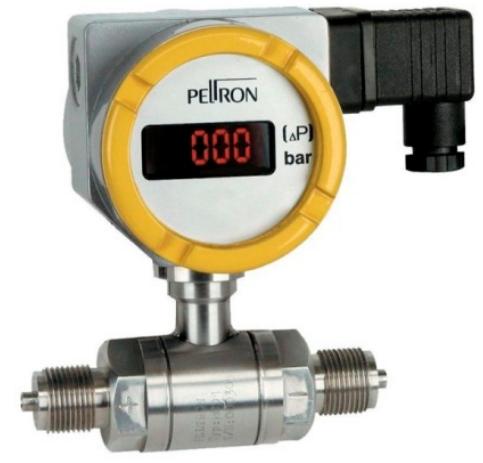

Figure 6. The PXWD differential pressure transducer [35].

The measuring points are located at a distance of $1 \mathrm{~m}$ from each other and are connected to the differential pressure transducer by means of impulse conductors. Additional conductors are also installed to connect a liquid U-tube manometer.

\section{Experimental Determination of The Friction Factor}

The experimental testing to determine the friction factor was carried out for horizontal and adiabatic water flows. A dedicated measuring segment of the test stand presented in Figure 3 was used for this purpose. The object of the testing was a rifled tube with internal helical ribs, as presented in Figures 4 and 5, with dimensions as listed in Table 2.

The measurements were performed using a PXWD differential pressure transducer (cf. Figure 6) and a liquid U-tube manometer. During each measuring series, the measured values were recorded every second. The obtained measuring data were divided into two groups: Values measured directly (the medium temperature) and values calculated based on values recorded at the current outputs (water volume flow and the difference in pressure between measuring points). In order to obtain as reliable values as possible, the measuring data were analyzed appropriately. The analysis covered both the directly measured values and those calculated based on the current signals transmitted by relevant sensors. The measurement uncertainty was determined based on the ASME standards [36]. The uncertainty determination consisted of finding the range, including $95 \%$ of values measured in a measuring series. The total uncertainty value takes into account uncertainties related to the applied measuring instrument, as well as those concerning the measuring conditions, including the 
impact of the observer and the measuring range of the applied devices. The uncertainty of the direct measurements is defined using the following relation:

$$
u(x)=\sqrt{u_{A}^{2}(x)+u_{B}^{2}(x)}
$$

Type $A$ uncertainty is found in the case of multiple measurements of a single quantity, and it is calculated as:

$$
u_{A}(x)=\sqrt{\frac{\sum_{i=1}^{n}\left(x_{i}-\bar{x}\right)^{2}}{n(n-1)}}
$$

where:

$n$-the number of measurements of a given quantity;

$\bar{x}$-the mean value of all measurements.

Type $B$ uncertainty components take into account the measuring instrument accuracy, and the uncertainty is calculated as:

$$
u_{B}(x)=\sqrt{\sum_{j} \frac{u_{j}}{3}}
$$

The components taken into account in Equation (18) are as follows: Calibration accuracy, measuring range, experimenter's errors, etc. The obtained measured data, together with the uncertainty analysis results, are listed in Table 3.

\begin{tabular}{|c|c|c|c|c|c|c|c|c|}
\hline No. & $\begin{array}{c}\text { Measured } \\
\text { Flow } \\
V \mathrm{~m}^{3} / \mathrm{h}\end{array}$ & $\begin{array}{c}\text { Fluid } \\
\text { Temperature } \\
t^{\circ} \mathrm{C}\end{array}$ & $\begin{array}{l}\text { Density } \\
\rho \mathrm{kg} / \mathrm{m}^{3}\end{array}$ & $\begin{array}{c}\text { Kinematic Viscosity } \\
\text { Coefficient } \\
v \mathrm{~m}^{2} / \mathrm{s}\end{array}$ & $\begin{array}{c}\text { Reynolds } \\
\text { Number } \\
\quad \operatorname{Re}\end{array}$ & $\begin{array}{c}\text { Measured } \\
\text { Differential Pressure } \\
\Delta p \mathrm{~Pa}\end{array}$ & $\begin{array}{c}\text { Friction } \\
\text { Factor } \\
f_{F}\end{array}$ & $\begin{array}{c}\text { Uncertainty } \\
u(f)\end{array}$ \\
\hline 1 & 8.028 & 22.8 & 997.59 & $9.43 \times 10^{-7}$ & 93195 & 2326.58 & 0.0204 & 0.0003 \\
\hline 2 & 7.800 & 23.0 & 997.55 & $9.40 \times 10^{-7}$ & 90888 & 2184.68 & 0.0203 & 0.0003 \\
\hline 3 & 7.580 & 23.2 & 997.50 & $9.35 \times 10^{-7}$ & 88751 & 2038.65 & 0.0200 & 0.0003 \\
\hline 4 & 7.331 & 23.4 & 997.45 & $9.31 \times 10^{-7}$ & 86231 & 1962.47 & 0.0206 & 0.0003 \\
\hline 5 & 7.079 & 23.6 & 997.41 & $9.27 \times 10^{-7}$ & 83623 & 1831.70 & 0.0206 & 0.0003 \\
\hline 6 & 6.811 & 23.7 & 997.39 & $9.25 \times 10^{-7}$ & 80613 & 1715.03 & 0.0209 & 0.0003 \\
\hline 7 & 6.564 & 23.7 & 997.37 & $9.24 \times 10^{-7}$ & 77790 & 1592.57 & 0.0208 & 0.0003 \\
\hline 8 & 6.294 & 23.9 & 997.34 & $9.21 \times 10^{-7}$ & 74849 & 1477.20 & 0.0210 & 0.0003 \\
\hline 9 & 6.054 & 24.0 & 997.29 & $9.17 \times 10^{-7}$ & 72282 & 1369.14 & 0.0211 & 0.0003 \\
\hline 10 & 5.763 & 23.9 & 997.32 & $9.19 \times 10^{-7}$ & 68648 & 1261.42 & 0.0214 & 0.0003 \\
\hline 11 & 5.512 & 24.1 & 997.27 & $9.15 \times 10^{-7}$ & 65934 & 1150.97 & 0.0214 & 0.0003 \\
\hline 12 & 5.147 & 21.7 & 997.85 & $9.67 \times 10^{-7}$ & 58279 & 1088.23 & 0.0232 & 0.0003 \\
\hline 13 & 4.942 & 21.5 & 997.89 & $9.70 \times 10^{-7}$ & 55768 & 986.23 & 0.0228 & 0.0003 \\
\hline 14 & 4.679 & 21.8 & 997.83 & $9.65 \times 10^{-7}$ & 53072 & 881.18 & 0.0227 & 0.0003 \\
\hline 15 & 4.454 & 21.8 & 997.83 & $9.65 \times 10^{-7}$ & 50523 & 815.94 & 0.0232 & 0.0003 \\
\hline 16 & 4.176 & 21.9 & 997.80 & $9.62 \times 10^{-7}$ & 47529 & 723.04 & 0.0234 & 0.0003 \\
\hline 17 & 3.946 & 21.9 & 997.80 & $9.62 \times 10^{-7}$ & 44894 & 656.44 & 0.0238 & 0.0003 \\
\hline 18 & 3.694 & 21.9 & 997.80 & $9.62 \times 10^{-7}$ & 42040 & 601.64 & 0.0249 & 0.0003 \\
\hline 19 & 3.441 & 22.0 & 997.79 & $9.61 \times 10^{-7}$ & 39214 & 536.43 & 0.0255 & 0.0003 \\
\hline 20 & 3.156 & 22.2 & 997.74 & $9.56 \times 10^{-7}$ & 36142 & 466.61 & 0.0264 & 0.0004 \\
\hline 21 & 2.912 & 22.0 & 997.78 & $9.60 \times 10^{-7}$ & 33211 & 397.07 & 0.0264 & 0.0004 \\
\hline 22 & 2.654 & 22.0 & 997.78 & $9.60 \times 10^{-7}$ & 30266 & 361.31 & 0.0289 & 0.0004 \\
\hline 23 & 2.400 & 22.1 & 997.75 & $9.58 \times 10^{-7}$ & 27426 & 307.55 & 0.0301 & 0.0004 \\
\hline 24 & 2.079 & 22.5 & 997.67 & $9.50 \times 10^{-7}$ & 23968 & 243.62 & 0.0318 & 0.0005 \\
\hline 25 & 2.074 & 22.4 & 997.68 & $9.51 \times 10^{-7}$ & 23883 & 246.31 & 0.0323 & 0.0005 \\
\hline
\end{tabular}

Table 3. Friction factor values obtained experimentally and calculated values of the measurement uncertainty.

The friction factor values determined experimentally were used to find the correlation for the friction factor $f_{F}$ :

$$
f_{F}=A \cdot \operatorname{Re}^{B} N^{C}\left(\frac{e}{d_{i}}\right)^{0.785} \beta^{0.78}
$$

where $A, B$, and $C$ are the searched coefficients.

Equation (19) was used to select coefficients to obtain values as close as possible to the measured ones. The form of Equation (19) is similar to the correlation (14) proposed in Reference [3]. The TableCurve 2D program [37] was used for this purpose. This program enables the user to 
input the form of the function. Appropriate coefficients were selected, and Equation (19) takes the following form:

$$
f_{F}=0.097 \cdot R e^{-0.255} N^{1.371}\left(\frac{e}{d_{i}}\right)^{0.785} \beta^{0.78}
$$

where: $\beta=30^{\circ}$ and $e / d_{i}=1 / 34.9$.

The developed correlation for the friction factor determination is not universal—it only concerns a tube with the geometry used during the testing. Further studies are needed to develop a universal correlation for tubes with similar inner diameters classed as tubes with micro-ribs. The experimental data and the curves illustrating changes in the values obtained from the developed Equation (20) and the Blasius equation (Equation (2)) concerning the friction factor value in smooth tubes are presented in Figure 7.

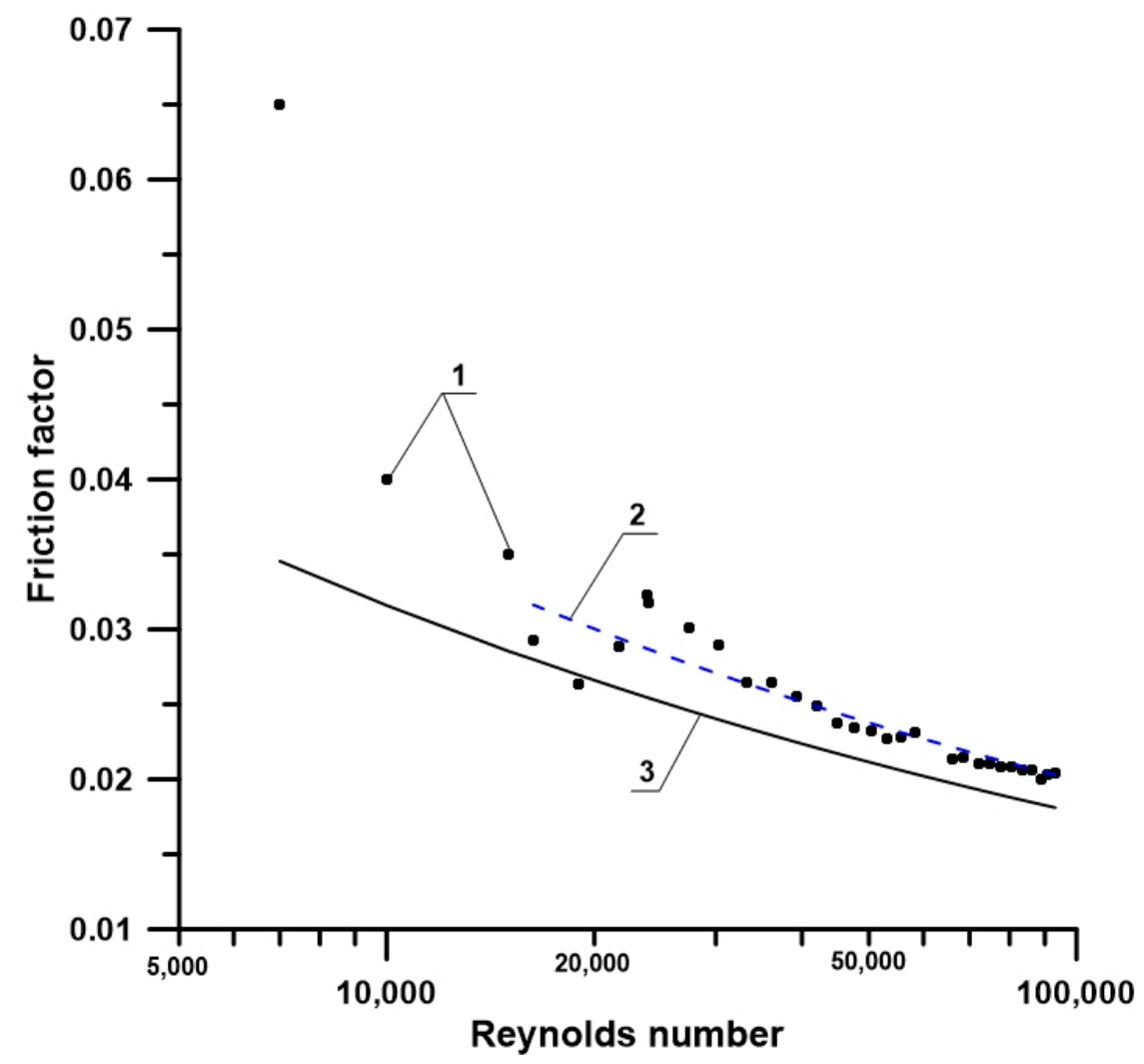

Figure 7. Friction factor values obtained experimentally and their comparison with smooth tubes; 1-experimental data; 2 -the proposed equation (Equation (20)); 3-the Blasius equation (Equation (2)).

The curve of Equation (20) is plotted for Reynolds numbers included in the range of 20,000 to $\sim 90,000$ to enable a comparison with the relations available from the literature. The function mapping range is limited to the Reynolds numbers given above because, for $\operatorname{Re} \approx 20,000$, a change in the character of the flow can be observed, from transitional to fully developed. General equations like Equation (19) cannot map the changes in the measured values. The development of a function for the transitional range requires many more measuring points from that range. 
The oscillations appear in the transitional flow region. Analysing available literature on the topic, it is found that for rifled tubes, the transitional region occurs for the Reynolds numbers from the range of $17,000 \div 21,000$. This can be seen when analysing Figure 7 . In the transitional region, the changes in the friction factor values are very big at small changes in the Reynolds number. Moreover, measurements of frictional pressure losses in small flows are burdened with random errors. The developed experimental data and the curve plotted for Equation (20) show values which are $10-15 \%$ higher compared to the friction factor in smooth tubes. This is due to the increased surface area of contact between the fluid and the wall. However, the rise in the friction factor value is not large because the number of ribs in the cross-section is small; the rib height-inner-diameter ratio suggests that the tested tube belongs to the category of tubes with micro-ribs, and the rib helical angle is not big enough to generate significant local disturbance to the flow. We argue that, apart from the observed transitional range of the flow, rifled tubes with micro-ribs and with diameters similar to those used in the experiment will demonstrate changes in friction factor values similar to those found for rough tubes. Comparing the obtained data with the Moody chart for industrial tubes, we estimated that, in terms of the friction factor, the used tube with internal ribs is comparable to tubes with a relative roughness of $\sim 0.002$.

The accuracy of the friction factor determination by means of Equation (20) compared to the values obtained experimentally is illustrated in Figure 8, which presents the calculated and measured values in a single chart.

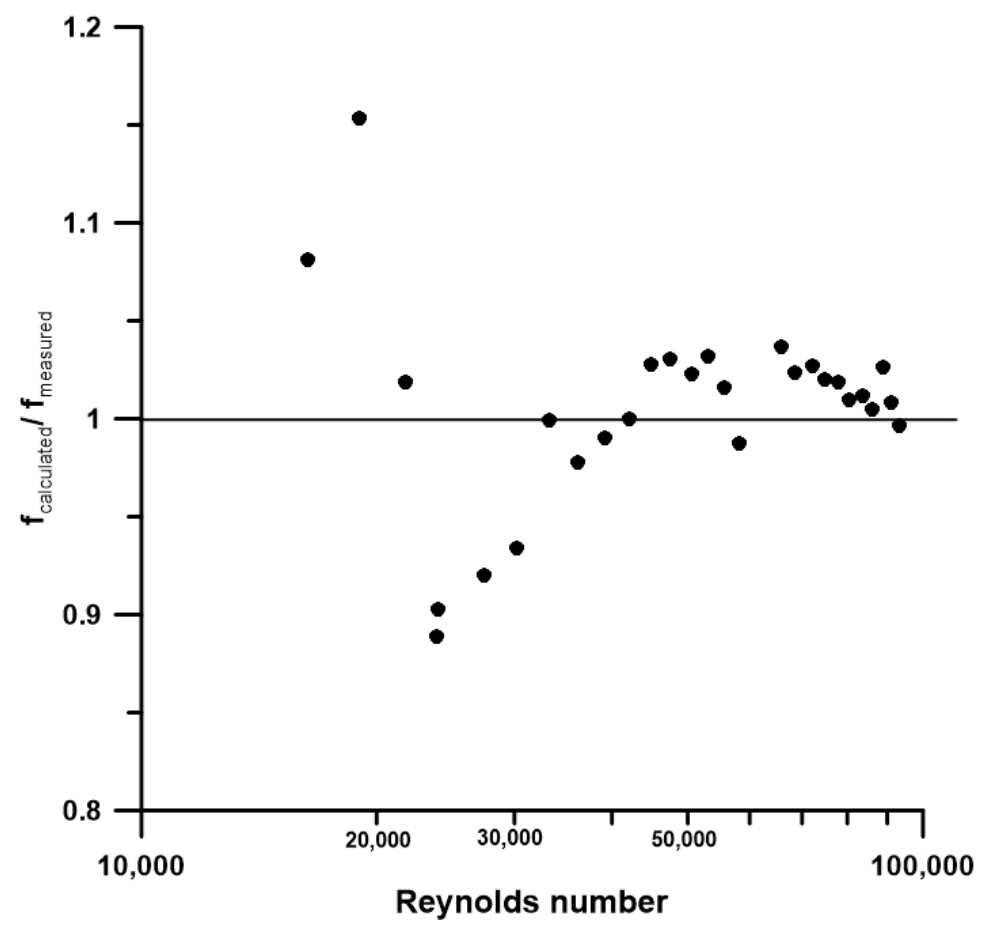

Figure 8. Comparison of calculated and measured values of the friction factor.

Good agreement between the friction factor values obtained using the two determination methods was achieved for Reynolds numbers higher than 35,000. Such comparisons are often found in scientific works; one of them is presented by Zdaniuk et al. [5].

The data obtained using a differential pressure transducer are also compared to the results of measurements performed with a U-tube. The friction factor values obtained by means of the two instruments and their relation to the developed correlation are presented in Figure 9. 
In both cases the obtained friction factor values are similar, and for high Reynolds numbers, individual results are very close to each other. Measurements using the analog method involve much higher measuring errors. In the case of measurements by means of the PXWD transducer, the measuring error totalled up to $5 \%$ of the measured value. For the U-tube, the differences reach $10 \%$. Such high differences in the latter case are primarily due to the observer's errors. Like in the case of the PXWD transducer measurements, they are caused by the flow character, which makes the water level in the U-tube rise and fall.

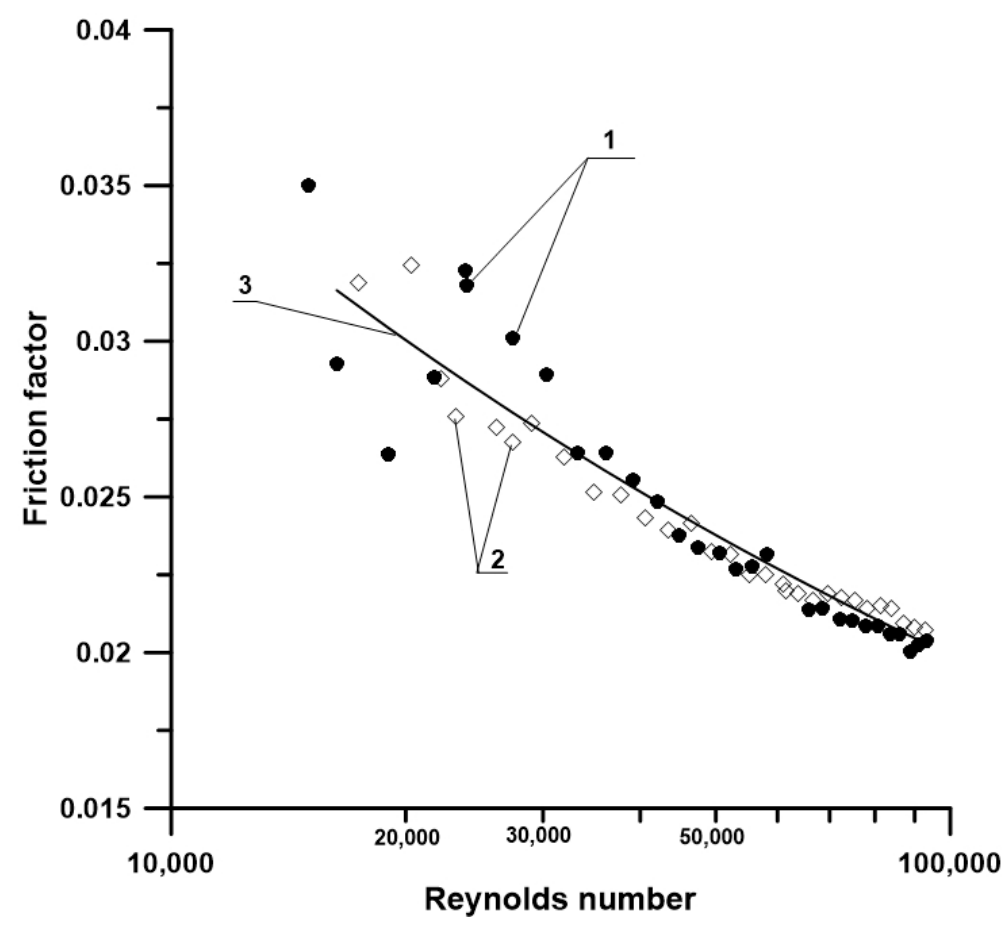

Figure 9. Comparison of the friction factor values obtained by means of a PXWD transducer and a U-tube in relation to the equation values; 1 -PXWD transducer; 2 -U-tube; 3-Equation (20).

Analyzing the obtained measuring data, attention should be drawn to the changes in the measured values of the friction factor. In the case of smooth tubes, the transitional-to-turbulent flow transition takes place when the Reynolds number totals several thousand. In the case of the tube under analysis, the transition occurs for Reynolds numbers from the range of 17,000-21,000. The authors of works concerning the testing of tubes with micro-ribs report similar observations $[3,5-7,38]$. Figure 10 presents a comparison of the data obtained from the measurements, the developed correlation, the formulae available from the literature, and the equation specific to smooth tubes.

The chart indicates that the nature of the friction factor values obtained from the measurements and the developed equation is closest to the results presented in Reference [2]. The good agreement between the results obtained from correlation (9) and correlation (20) confirms the correctness of the performed measurements. In further calculations, either Equation (20) or Equation (9) can be used. The results produced by the other correlations are different. This may be due to the fact that Equations (11), (13), and (14) were developed based on the results obtained for flows through tubes with diameters roughly half the size of the diameter of the tube used in the present experiment. Other significant factors are the number of ribs, rib geometry, and helical angle. The internally ribbed tube used herein has a small number of ribs, and their helical angle is $30^{\circ}$. 


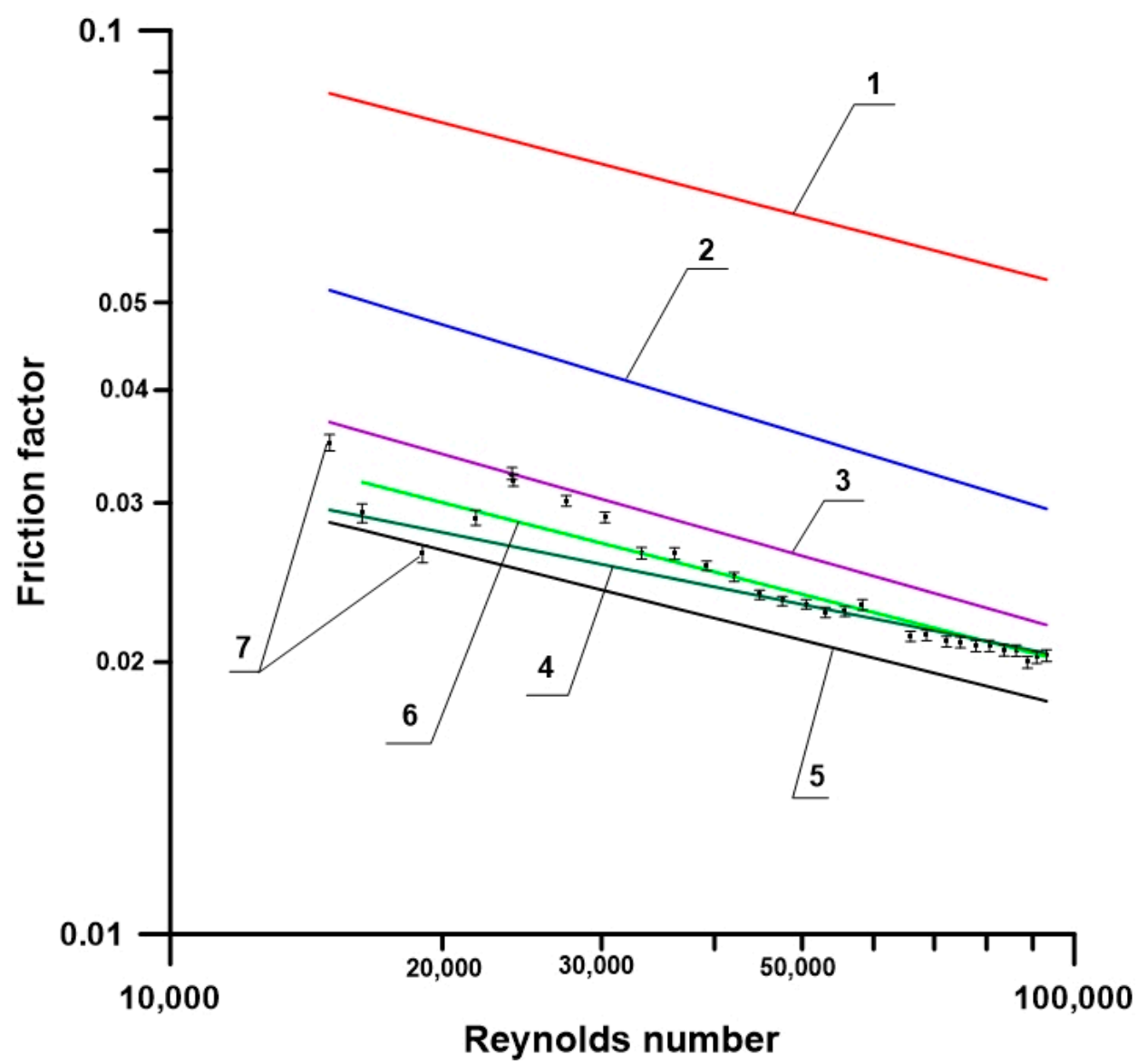

Figure 10. Comparison of the experimental data with the correlations defining the friction factor in rifled tubes with internal helical ribs and smooth tubes; 1-Equation (13); 2-Equation (11); 3-Equation (14);.4-Equation (9); 5-Equation (2); 6-the proposed equation (Equation (20)); 7—experimental data.

\section{Conclusions}

This paper presents an analysis of flow phenomena occurring in rifled tubes with internal helical ribs. Correlations are developed that describe the friction factor-related phenomena. The experimental testing results indicate that if the tube internal geometry is extended, there is a slight rise in frictional pressure losses compared to smooth tubes. Due to the application of a micro-rib and a diameter about twice as large as the one used in the testing performed and described in the works published so far, the increase in friction-related pressure losses is not very distinct. The curves obtained using the developed correlation and other state-of-the-art correlations are shown in Figure 10. The good agreement between the results obtained from correlation (9) and correlation (20) confirms the correctness of the performed measurements. In further calculations, either Equation (20) or Equation (9) can be used.

When comparing the trends regarding linear friction-related pressure losses, it is evident that tubes with internal helical micro-ribs behave in the same manner as tubes with a specific relative roughness.

The previously observed phenomenon of a shift in the transition from the transitional to the fully developed flow was confirmed during the testing. According to the reference literature data, the transition occurs for the Reynolds number value of $\sim 20,000$. The presented measuring data make the transition clearly visible. Relating the phenomenon to smooth tubes, the flow changes its character from transitional to fully developed when the Reynolds number takes values below 5000 . The developed correlations enabling friction factor determination are not universal-they concern tubes with internal geometry equal to those used during the testing. Further studies are needed to develop universal correlations for tubes with similar inner diameters classed as tubes with micro-ribs. 
Transitional flows may be another subject of future research. Observations presented in the literature concerning the flow structure change to the turbulent flow for the Reynolds number value of $\sim 20,000$ are confirmed.

The results of the testing of friction-related pressure losses indicate that the tube's analyzed geometry involves a rise in the friction factor of $~ 10-15 \%$ compared to smooth tubes with the same diameter. The developed experimental correlations cannot be applied to a bigger group of tubes with internal helical ribs as this requires more measurements using a greater number of tubes with a similar internal geometry.

Author Contributions: Conceptualization, S.G.; Methodology, S.G.; Software, S.G. and K.M.; Validation, K.M.; Formal Analysis, S.G. and K.M.; Investigation, K.M.; Data Curation, K.M.; Writing-Original Draft Preparation, S.G.; Writing-Review \& Editing, S.G.; Visualization, K.M.; Supervision, S.G.; Project Administration, S.G.

Funding: This research received no external funding.

Conflicts of Interest: The authors declare no conflict of interest.

\section{Nomenclature}

a rib width at the base, $\mathrm{mm}$

A area, $\mathrm{mm}^{2}$

$A_{n} \quad$ tube cross-section surface area (ribs not taken into account), $\mathrm{mm}^{2}$

$A_{x s} \quad$ tube cross-section surface area minus the surface area occupied by ribs, $\mathrm{mm}^{2}$

$b \quad$ rib average width, $\mathrm{mm}$

$d_{h} \quad$ hudraulic diameter, $\mathrm{mm}$

$d_{0} \quad$ outer diameter, $\mathrm{mm}$

$d_{i} \quad$ inner diameter (without ribs), $\mathrm{mm}$

$d_{\min } \quad$ minimum diameter, $\mathrm{mm}$

e rib height, $\mathrm{mm}$

$f \quad$ friction factor of smooth tubes

$f_{F} \quad$ friction factor of rifled tubes,-

$g \quad$ wall thickness, $\mathrm{mm}$

$N$ number of ribs in the cross-section, -

$O \quad$ wetted perimeter, $\mathrm{m}$

$p \quad$ pitch, $\mathrm{mm}$

Re Reynolds number

$u \quad$ uncertainty

$V \quad$ volumetric flow, $\mathrm{m}^{3} / \mathrm{h}$

Greek symbols

$\alpha \quad$ rib apex angle,

$\beta \quad$ rib helical angle,

$\Delta p \quad$ differential pressure, $\mathrm{Pa}$

$\rho \quad$ density, $\mathrm{kg} / \mathrm{m}^{3}$

$v \quad$ kinematic viscosity coefficient, $\mathrm{m}^{2} / \mathrm{s}$

\section{References}

1. Kakac, S.; Bergles, A.; Mayinger, F.; Yuncu, H. (Eds.) Heat Transfer Enhancement of Heat Exchangers; Springer: Dordrecht, The Netherlands, 1999; ISBN 978-94-015-9159-1. [CrossRef]

2. Carnavos, T.C. Cooling of Air in Turbulent Flow with Internally Finned Tubes. Heat Transf. Eng. 1979, 1, 41-46. [CrossRef]

3. Webb, R.; Narayanamurthy, R.; Thors, P. Heat Transfer and Friction Characteristics of Internal Helical-Rib Roughness. J. Heat Transf. 2000, 122, 134-142. [CrossRef]

4. Hewitt, G.; Shires, G.; Bott, T. Process Heat Transfer, 1st ed.; CRC Press: London, UK, 1994; pp. 297-325, ISBN 0-8493-9918-1.

5. Zdaniuk, G.J.; Chamra, L.M.; Mago, P.J. Experimental determination of heat transfer and friction in helically-finned tubes. Exp. Therm. Fluid Sci. 2008, 32, 761-775. [CrossRef] 
6. Zdaniuk, G.J.; Chamra, L.M.; Walters, D.K. Correlating heat transfer and friction in helically-finned tubes using artificial neural networks. Heat Mass Transf. 2008, 50, 4713-4723. [CrossRef]

7. Zdaniuk, G.J.; Luck, R.; Chamra, L.M. Linear correlation of heat transfer and friction in helically-finned tubes using five simple groups of parameters. Heat Mass Transf. 2008, 51, 3548-3555. [CrossRef]

8. Cheng, L.; Chen, T. Study of vapour liquid two-phase frictional pressure drop in a vertical heated spirally internally ribbed tubes. Chem. Eng. Sci. 2007, 62, 783-792. [CrossRef]

9. Weiguo, X.; Depeng, R.; Qing, Y.; Guodong, L.; Huilin, L.; Shuai, W. Simulations and experiments of laminar heat transfer for Therminol heat transfer fluids in a rifled tube. Appl. Therm. Eng. 2016, 102, 861-872. [CrossRef]

10. Solutia Inc. Therminol 55. Heat Transfer Fluid by Solutia; Solutia Inc.: St. Louis, MO, USA, 2008.

11. Ackerman, J. Pseudoboiling Heat Transfer to Supercritical Pressure Water in Smooth and Ribbed Tubes. J. Heat Transf. 1969, 92, 490. [CrossRef]

12. Gee, D.; Webb, R. Forced convection heat transfer in helically rib-roughened tubes. Int. J. Heat Mass Transf. 1980, 23, 1127-1136. [CrossRef]

13. Zimparov, V.; Vulchanov, N.; Delov, L. Heat transfer and friction characteristics of spirally corrugated tubes for power plant condensers-1. Experimental investigation and performance evaluation. Int. J. Heat Mass Transf. 1991, 34, 2187-2197. [CrossRef]

14. Ravigururajan, T.; Bergles, A. Development and verification of general correlations for pressure drop and heat transfer in single-phase turbulent flow in enhanced tubes. Exp. Therm. Fluid Sci. 1996, 13, 55-70. [CrossRef]

15. Cheng, L.; Chen, T.; Luo, Y. Flow boiling heat transfer of kerosene inside ribbed tube. ASME Heat Transf. Div. 1997, 351, 235-241.

16. Dong, Y.; Huixiong, L.; Tingkuan, C. Pressure drop, heat transfer and performance of single-phase turbulent flow in spirally corrugated tubes. Exp. Therm. Fluid Sci. 2001, 24, 131-138. [CrossRef]

17. Barba, A.; Rainieri, S.; Spiga, M. Heat transfer enhancement in a corrugated tube. Int. Commun. Heat Mass Transf. 2002, 29, 313-322. [CrossRef]

18. Vicente, P.; Garcia, A.; Viedma, A. Mixed convection heat transfer and isothermal pressure drop in corrugated tubes for laminar and transition flow. Int. Commun. Heat Mass Transf. 2004, 31, 651-662. [CrossRef]

19. Wang, J.; Li, H.; Guo, B.; Yu, S.; Zhang, Y.; Chen, T. Investigation of forced convection heat transfer of supercritical pressure water in a vertically upward internally ribbed tube. Nuclear Eng. Des. 2009, 239, 1956-1964. [CrossRef]

20. Wang, J.; Li, H.; Yu, S.; Chen, T. Investigation on the characteristics and mechanism of unusual heat transfer of supercritical pressure water in vertically-upward tubes. Int. J. Heat Mass Transf. 2011, 54, 1950-1958. [CrossRef]

21. Yang, D.; Pan, J.; Zhou, C.; Zhu, X.; Bi, Q.; Chen, T. Experimental investigation on heat transfer and frictional characteristics of vertical upward rifled tube in supercritical CFB boiler. Exp. Therm. Fluid Sci. 2011, 35, 291-300. [CrossRef]

22. Khoeini, D.; Akhavan-Behabadi, M.; Saboonchi, A. Experimental study of condensation heat transfer of R-134a flow in corrugated tubes with different inclinations. Int. Commun. Heat Mass Transf. 2012, 39, 138-143. [CrossRef]

23. Ji, W.-T.; Zhang, D.-C.; He, Y.-L.; Tao, W.-Q. Prediction of fully developed turbulent heat transfer of internal helically ribbed tubes-An extension of Gnielinski equation. Int. J. Heat Mass Transf. 2012, 55, 1375-1384. [CrossRef]

24. Lu, J.; Sheng, X.; Ding, J.; Yang, J. Transition and turbulent convective heat transfer of molten salt in spirally grooved tube. Exp. Therm. Fluid Sci. 2013, 47, 180-185. [CrossRef]

25. Li, Z.; Tang, G.; Wu, Y.; Zhai, Y.; Xu, J.; Wang, H.; Lu, J. Improved gas heaters for supercritical $\mathrm{CO}_{2}$ Rankine cycles: Considerations on forced and mixed convection heat transfer enhancement. Appl. Energy 2016, 178, 126-141. [CrossRef]

26. Yang, Z.; Chen, W.; Chyu, M.K. Numerical study on the heat transfer enhancement of supercritical $\mathrm{CO}_{2}$ in vertical ribbed tubes. Appl. Therm. Eng. 2018, 145, 705-715. [CrossRef]

27. Xu, W.; Wang, S.; Liu, G.; Zhang, Q.; Hassan, M.; Lu, H. Experimental and numerical investigation on heat transfer of Therminol heat transfer fluid in an internally four-head ribbed tube. Int. J. Therm. Sci. 2017, 116, 32-44. [CrossRef] 
28. Zhang, Q.; Li, H.; Zhang, W.; Li, L.; Lei, X. Experimental study on heat transfer to the supercritical water upward flow in a vertical tube with internal helical ribs. Int. J. Heat Mass Transf. 2015, 89, 1044-1053. [CrossRef]

29. Shen, Z.; Yang, D.; Mao, K.; Long, J.; Wang, S. Heat transfer characteristics of water flowing in a vertical upward rifled tube with low mass flux. Exp. Therm. Fluid Sci. 2016, 70, 341-353. [CrossRef]

30. Massoud, M. Engineering Thermofluids. Thermodynamics, Fluid Mechanics, and Heat Transfer; Springer: Berlin/Heidelberg, Germany, 2005; ISBN 978-3-540-27280-9.

31. Majewski, K. Concept of a measurement and test station for determining linear pressure drop and heat transfer coefficient of internally ribbed tubes. J. Power Technol. 2013, 93, 340-346.

32. Pan, J.; Yang, D.; Dong, Z.; Zhu, T.; Bi, Q. Experimental investigation on heat transfer characteristic of low mass flux rifled tube with upward flow. Int. J. Heat Mass Transf. 2011, 54, 2952-2961. [CrossRef]

33. Zhu, X.; Bi, Q.; Su, Q.; Yang, D.; Wang, J.; Wu, G.; Yu, S. Self-compensating characteristic of steam-water mixture at low mass velocity in vertical upward parallel internally ribbed tubes. Appl. Therm. Eng. 2010, 30, 2370-2377. [CrossRef]

34. Grądziel, S.; Majewski, K. Simulation of Thermal and Flow Phenomena in Smooth and Internally Rifled Tubes. J. Heat Transf. Eng. 2018, 39, 1243-1250. [CrossRef]

35. Peltron. Available online: www.peltron.pl (accessed on 6 June 2017).

36. ASME International. Policy on Reporting Uncertainties in Experimental Measurements and Results. J. Heat Transf. Policy 1993, 115, 5-6. [CrossRef]

37. Systat Software, Inc. TableCurve 2D-Curve Fitting Made Fast and Easy. Available online: http://www. sigmaplot.co.uk/products/tablecurve2d/tablecurve2d.php (accessed on 5 June 2017).

38. Jensen, M.; Vlakancic, A. Technical note. Experimental investigation of turbulent heat transfer and fluid flow in internally finned tubes. Heat Mass Transf. 1999, 42, 1343-1351. [CrossRef]

(C) 2019 by the authors. Licensee MDPI, Basel, Switzerland. This article is an open access article distributed under the terms and conditions of the Creative Commons Attribution (CC BY) license (http://creativecommons.org/licenses/by/4.0/). 